\title{
Incidence and Clinical Characteristics of the Infection by the Respiratory Syncytial Virus in Children Admitted in Santa Casa de São Paulo Hospital
}

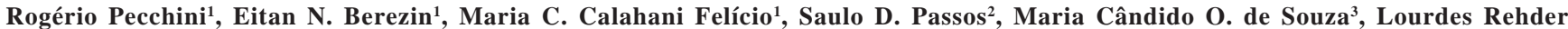 \\ de Andrade Vaz de Lima ${ }^{3}$, Mirthes Ueda ${ }^{3}$, Tokiko Kyomen Matsumoto ${ }^{3}$ and Edison L. Durigon ${ }^{4}$ \\ ${ }^{1}$ Pediatric Department of the Irmandade da Santa Casa de Misericórdia de São Paulo, São Paulo, SP; ${ }^{2}$ School of Medicine of Jundiaí, \\ Jundiaí, SP; ${ }^{3}$ Institute Adolfo Lutz, São Paulo, SP; ${ }^{4}$ Institute of Biomedical Sciences, University of São Paulo, São Paulo SP; Brazil
}

\begin{abstract}
The purpose of this study was to identify the rate of infections due to RSV and other viruses in children. In addition we have analyzed demographic data and clinical characteristics of the RSV-positive patients comparing with patients infected by other respiratory viruses. We also described the seasonality of the RSV occurrence in a hospital in São Paulo. Children below 5 years old admitted in Santa Casa de São Paulo Hospital between February 2005 and September 2006 due to acute respiratory infections (ARI) were included. A nasopharyngeal specimens were obtained with sterile No. 5 French feeding catheters as soon as possible (usually within $24 \mathrm{~h}$ ). Specimens were kept refrigerated at $4^{\circ} \mathrm{C}$ and transported to Adolfo Lutz Institute, where the indirect immunofluorescent assay was performed. Virus identified by these assay included RSV, Adenovirus, Influenza A and B virus and Parainfluenza 1, 2, and 3. Clinical data from each group was compared. Four hundred and fifty five cases were included in the study, with $30 \%$ positive for some type of virus. Viruses that were identified included Respiratory Syncytial Virus (73.03\%), Influenza (8.42\%), Parainfluenza (8.42\%) and Adenovirus (3.37\%). We divided the subjects in 3 groups: Group 1 RSV-Positive, Group 2 Other Positive Viruses and Group 3 Negative for Respiratory Virus. Mean age (months) was of 7.5 for RSVpositive children, $\mathbf{7 . 6}$ for other viruses, and 8 for negative for respiratory virus. The RSV-Positive Group was significantly younger than the Group Negative for Respiratory Virus $(\mathbf{p}<\mathbf{0 . 0 5})$. Signs of UAI were more present in the Positive RSV Group ( $\mathbf{2} \mathbf{0 . 0 5}$ ). General mortality was of $2.41 \%$. There was a higher incidence of RSV between the months of March and August in the two years of the study. Our study indicates RSV as the most prevalent viral agent in children admitted due to (ARI), especially in infants below 3 months old. We have also found that infections due to RSV can occur in months others than the classic seasonal period.
\end{abstract}

Key-Words: Children, bronchiolitis, RSV, respiratory infections.

Acute respiratory infections (ARI) are an important cause of morbidity and mortality among children worldwide [1-3]. According to data from the World Health Organization in 2002, they account for up to 3.96 millions of deaths in that age range [3]. Two thirds of these deaths occur in children under one year old, and $90 \%$ in developing countries [1,3].

Viral infections are the most frequent etiological agents for acute respiratory infections, and are responsible for a significant morbidity and mortality in children [4]. Respiratory syncytial virus (RSV) is the most frequent etiologic agent of Lower Respiratory Tract Illness (LRTI) [3] in infants worldwide. Influenza viruses type A and B (FLU A/B), Parainfluenza virus (PIV), Adenovirus (ADV), and human Metapneumovirus (hMPV) are other important viral etiologic agents of LRTI [4].

The purpose of this study was to identify the rate of infections due to RSV and other viruses in children. In addition, we have analyzed demographic data and clinical characteristics of the RSV-positive patients comparing with patients infected by other respiratory viruses. We also described the seasonality of the RSV occurrence in a hospital in São Paulo, SP, Brazil.

Received on 27 May 2008; revised 29 October 2008.

Address for correspondence: Dr. Eitan Berezin. Av. Roberto Lorenz 482 - Zip code: 056110 50. São Paulo SP, Brazil. Phone: (55+11) 32584361. Fax: (55+11) 3331 0289. E-mail: berezin@terra.com.br. Financial Source: FAPESP, with Santa Casa de São Paulo being a participant of the VGDN (Viral Genetic Diversity Network) project.

The Brazilian Journal of Infectious Diseases 2008;12(6):476-479. (C) 2008 by The Brazilian Journal of Infectious Diseases and Contexto Publishing. All rights reserved.

\section{Material and Methods}

This prospective study was conducted from February 2005 to September 2006, at the Pediatric unit at Santa Casa de São Paulo University Hospital. This hospital is a public general hospital that localized in dowtown São Paulo.

The Internal Research Review Board from Santa Casa de São Paulo University Hospital approved this study.

During the period of study all admissions to the pediatric wards of the hospital were screened in order to determine the cause of hospitalization.

Inclusion criteria were: children age below 60 months with LRTI and symptoms duration less than 5 days. LRTI was defined by the presence of respiratory symptoms like cough, rhinorrhea, stridor, respiratory difficulty and abnormalities on physical examination including respiratory distress, wheezing or crackles. Chest roentgenogram abnormalities considered were air-trapping and alveolar infiltrates. Children with wheezing and/or signs of airtrapping on chest roentgenogram were considered to have bronchiolitis. Demographic and clinical information was recorded in standardized data.

A nasopharyngeal specimens were obtained with sterile No. 5 French feeding catheters as soon as possible (usually within $24 \mathrm{~h}$ ). Specimens were kept refrigerated at $4^{\circ} \mathrm{C}$ and transported to Adolfo Lutz Institute, where the indirect immunofluorescent assay was performed. Virus identified by these assay included RSV, Adenovirus, Influenza A and B virus and Parainfluenza 1, 2, and 3. Clinical data from each group were compared. 


\section{Statistical Analysis}

Demographic and clinical characteristics were compared between subjects in whom a viral etiology could be determined and those with negative viral studies. Comparisons between proportions among RSV positive, other positive viruses, and negative were performed by using the chi-square test, with Fisher's exact test with frequencies lower than five. For continuous variables, the Mann-Whitney Test was performed. A significance level was established at $\mathrm{p}=0.05$.

\section{Results}

Between February 2005 and September 2006, 455 cases were included in the study, which accounted for $34.8 \%$ of the cases admitted due to ARI in our Department in the same period. The female gender proportion was 46.4\%. Average age in months was 12.52 months (+ 12.76), and median age was 7.90 months. From the population included in the study, 306 cases (67.2\%) were younger than 1 year old.

A viral agent was detected in 178 (30.2\%) specimens. Viruses that were identified included Respiratory Syncytial Virus (73.03\%), Influenza (8.42\%), Parainfluenza (8.42\%) and Adenovirus (3,37\%). Most of the children included in the study (67.3\%) were younger than 1 year of age. The number of subjects who had a virus identified according to age are shown in Figure 1.

The most frequent symptoms identified were cough in 92.3\%, upper airways infection (UAI), characterized by runny nose, nasal obstruction or sneezes was found in $64.71 \%$, and fever in $62.4 \%$ of the cases. Increase in respiratory effort and/ or an increase in respiratory rate for age were present in 58\% of the patients.

We divided the subjects in 3 groups: Group 1 RSV-Positive, Group 2 Other Positive Viruses and Group 3 Negative for Respiratory Virus. Tables 1 and 2 indicate demographic characteristics and clinical data, and outcome of the 3 Groups.

Figure 1. Proportions of RSV Positive, Other Positive Viruses, and Negative Groups in the age ranges in months with less than one year each three months.

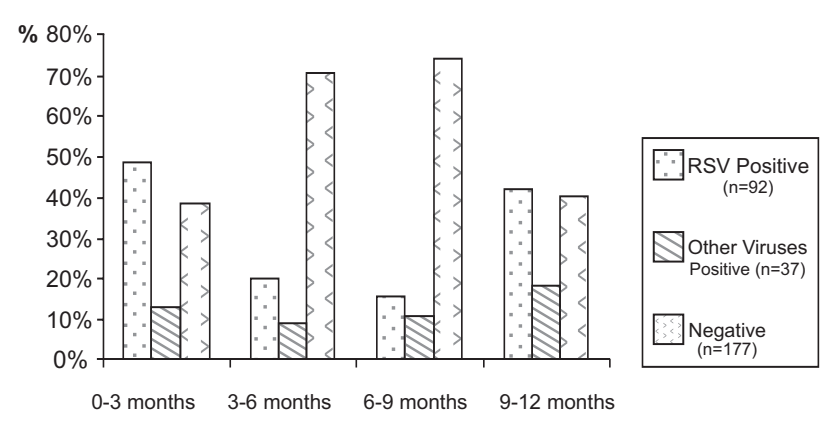

Figure 2 shows the distribution of the 3 Groups by month. The following proportions have been observed in the RSV positive group throughout 2005: 36.8\% in March, 24.1\% in April, 20\% in May, 29.4\% in June, 50\% in July, 26.3\% in August, $25 \%$ in September, $28.6 \%$ in November. In 2006: $22.7 \%$ in March, 45.6\% in April, 34.7\% in May, 10.2\% in June, 28.1\% in July, $42.8 \%$ in August, and 20\% in September. In the months not mentioned there was no incidence of RSV.

The mean hospital stay in days was $10.5(+15.9)$, and the median was 5 . Within the study population, 56 (12.3\%) patients were admitted in Intensive Care Unit (ICU), and 11 (2.4\% ) died. From the 11 deaths, 2 were included in the RSV positive group, 4 in the Other positive viruses group, and 5 in the Negative group.

\section{Discussion}

Respiratory viruses are responsible for a large proportion of respiratory infections, including LRTI. Despite their importance there have been few studies to determine the contribution of these agents to LRTI in Brazil.

$\mathrm{RSV}$ is the main respiratory pathogen causing LRTI in children, especially among young infants [1,6-8]. Virtually all children have been infected by RSV by 2 years of life and reinfections are common. In developed countries RSV is the major cause of LRTI in young children $[4,9,10]$. During this study RSV was detected in $73 \%$ of the positive samples and in $28 \%$ of all subjects included $[4,9,10]$.

The Figure 1 indicates that RSV is most frequent in younger subjects. RSV was present in $30 \%$ of the subjects below 1 year old and in $50 \%$ of the subjects below 3 months of age. This tendency toward younger age in RSV infections has been reported in others studies [4,11-13]. Anatomic and physiologic aspects might be indicated as responsible by a greater severity and need for hospitalization in the younger age [14].

Figure 2. Occurrence frequency of Negative, RSV Positive, and Other Positive Viruses Groups each month within the study period.

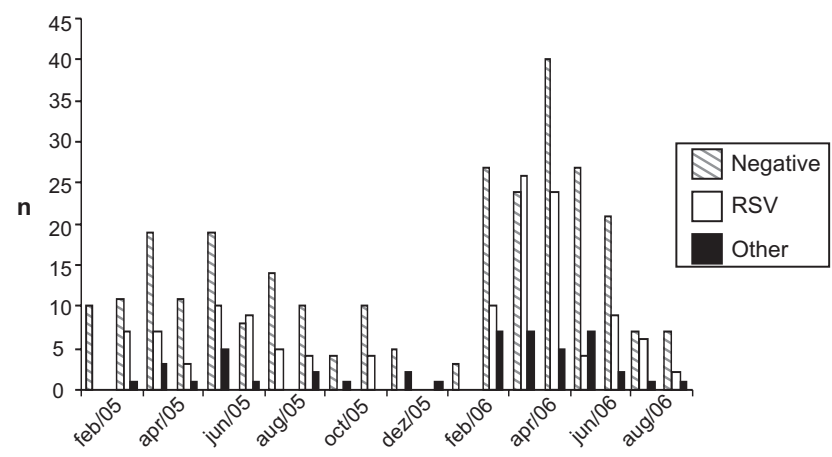


Table 1. Age in months, hospital admission length in days for children of Group 1-RSV-Positive, Group 2-Other Positive Viruses and Group 3-Negative for Respiratory Virus.

\begin{tabular}{lccc}
\hline Characteristics & Group 1 (n=130) & Group2 (n=48) & Group 3 (n=277) \\
\hline Age (months) & & & \\
Average + Std Deviation & $10.9+11.5^{*}$ & $9.3+8.1$ & $13.7+13.7$ \\
Median & $7.5(0.03-50.9) \dagger$ & $7.6(1.1-33)$ & $8(0.2-59.8)$ \\
Hospital admission period (days) & $7.78+11.35$ & $11.95+15.3$ & $13.99+47.46$ \\
Average & $5(1-88) \dagger$ & $6(1-80)$ & $5(1-750)$ \\
Median & * p $<0.05$, comparison between patients with positive IFI for RSV and negative IFI. $\dagger$ The number between parenthesis is the variation.
\end{tabular}

Table 2. Clinical profile data, physical examination, and outcome of subjects of Group 1-RSV-Positive, Group 2-Other Positive Viruses and Group 3-Negative for Repiratory Virus.

\begin{tabular}{lccc}
\hline & Group 1 (n=130) & Group 2 (n=48) & Group 3 (n=277) \\
\hline Clinical profile data (\%) & & & \\
$\quad$ Fever & 66.15 & 43.75 & $62.10^{*}$ \\
UAI $\dagger$ & 95.38 & 89.58 & 91.30 \\
Cough & 91.33 & 89.58 & 91.33 \\
Physical examination data & & & \\
$\quad$ Whistles & 49.23 & 58.33 & 54.87 \\
Dyspnea & 62.30 & 58.33 & 55.95 \\
ICU admission & 9.23 & 14.58 & 9.02 \\
Death & 1.53 & $8.33 \ddagger$ & 1.80 \\
\hline
\end{tabular}

* $\mathrm{p}<0.05$, comparison between patients with negative IFI and other viruses. $\dagger$ UAI, upper airways infection, characterized by runny nose, nasal obstruction or sneezes. $\neq \mathrm{p}<0.05$, comparison between patients with IFI positive for Other Viruses, with RSV Positive, and with Negative Groups.

The classic clinical profile described for RSV infection is characterized by the impairment of the upper airways, with a light-colored nasal secretion, moderate cough, and low hyperthermia, followed by the impairment of the lower airways $[19,20]$. All children included in this study had signs of impairment in the lower airways. UAI symptoms and fever were more present in the RSV Positive Group, when compared to the Other Positive Viruses Group, or the Negative Group, Durani et al. [21] concluded that cough, and retractions are predictive signals of RSV infection in young infants when studying the clinical signs of the respiratory infection by RSV in 197 children below 36 months.

RSV seasonality found in this study, indicating a large incidence between the months of March and August in both years, is an acknowledged epidemiological aspect. The larger RSV incidence occurs during the colder months of the year, which agrees with studies performed in the cities of São Paulo and Rio de Janeiro [7,24,25]. The same results have been found in Latin American countries, such as Argentina and Uruguay $[14,26]$. In Northeastern Brazilian cities, such as Salvador, Bahia state, the incidence of RSV is larger in the rainy period [11].

In our study we have found subjects with RSV infection in November 2005 (28.57\%), which is not a part of the season period described. Bosso et al. [12] (2004) have also found an incidence peak of RSV outside the seasonal period in a study performed in Botucatu, São Paulo state, when evaluating the incidence of that virus in children below 2 years old.
Prophylaxis for RSV infection currently available performed with palivizumabe is shown to be effective, but is indicated for children considered as in risk of developing more severe infections due to the virus (premature infants and infants with chronic pulmonary and cardiovascular diseases), and must be administered for a month before the larger incidence period [27]. Our casuistics show an incidence peak out of the characteristic seasonal period, thus showing the need to observe more series of cases further in order to know whether that fact has occurred independently.

Prophylaxis for RSV with palivizumabe is show to be efficient in decreasing the need for hospital stay, as well as the need for oxygen in risk populations, characterized by prematurity, bronchodysplasia patients, congenital cardiopathies for pulmonary hyperflow and immunodeficiencies [28]. Studies on the costs of the application of human monoclonal immunoglobulin in prophylaxis have been made, as the one from Rodriguez et al. [29], in Argentina, showing that despite the high cost, prophylaxis is efficient in decreasing the hospital admission rates in high risk populations.

Mortality rates related to infections by RSV are indicated as less than $1 \%$ in healthy children population [22]. A study performed with hospital admitted children below 2 years old, in the rural region of Asia, has indicated a mortality rate related to RSV of $1.9 \%$ [30]. In our casuistic, death rate was of $2.41 \%$, with 1.53\% in RSV Positive Group, 8.33\% in the Other Positive Virus Group, and $1.80 \%$ in the Negative Group. In the RSV 
Positive Group, two deaths occurred to children below two months old. This data point to a greater severity in the infection caused by RSV in young infants, in chronic pulmonary disease, congenital cardiac disease, premature infants and children with immunodeficiency [31,32].

Our study indicates RSV as the most prevalent viral agent in children admitted due to ARI, especially in infants below 3 months old. We have also found that infections due to RSV can occur in months others than the classic seasonal period.

\section{References}

1. Lourenção L.G., Junior J.B.S., Rahal P., et al. Infecção pelo Vírus Sincial Respiratório em crianças. Pulmão RJ. 2005;14(1):59-68.

2. WHO. The World Health Report 2004 -changing history. World Healh Organization, Geneva, Switzerland. 2004.

3. Cabello C., Manjarrez M., Olvera R., et al. Frequency of viruses associated with acute respiratory infections in children younger than five years of age at a locality of Mexico City. Mem Inst Oswaldo Cruz 2006;10(1):21-4.

4. Costa L.F., Yokosawa J., Mantese O.C., et al. Respiratory viruses in children younger than five years old with acute respiratory disease from 2001 to 2004 in Uberlândia, MG, Brazil. Mem Inst Oswaldo Cruz 2006;101(3):301-6.

5. Brouard J., Vabret A., Nimal-Cuvillon D., et al. Epidemiology of acute upper and lower respiratory tract infections in children. Rev Prat 2007 oct 31;57(16):1759-66.

6. Bloomfield P., Dalton D., Karleka A., et al. Bacteraemia and antibiotic use in respiratory syncytial virus infections. Archives of disease in childhood 2004 Apr;89(4):363-7.

7. D’Elia C., Siqueira M.M., Portes S.A., Sant'Anna C.C. Infecções do trato respiratório inferior pelo vírus sincial respiratório em crianças hospitalizadas menores de um ano de idade. Rev Soc Bras Med Trop 2005;38(1):7-10.

8. Weber M.W., Milligan P., Sanneh M., et al. An epidemiological study of RSV infection in the Gambia. Bulletin of the World Health Organization 2002;80(7):562-8.

9. Calegari T., Queiroz D.A.O., Yokosawa J., et al. ClinicalEpidemiological Evaluation of Respiratory Syncytial Virus Infection in Children Attended in a Public Hospital in Midwestern Brazil. Braz J Infect Dis 2005;9(2):156-61.

10. Straliotto S.M., Siqueira M.M., Muller R.L., et al. Viral etiology of acute respiratory infections among children in Porto Alegre, RS, Brazil. Rev Soc Bras Med Trop 2002 JulAug;35(4):283-91.

11. Moura F.E.A., Borges L.C., Souza L.S.F., et al. Estudo de infecções respiratórias agudas virais em crianças atendidas em um centro pediátrico em Salvador (BA). Jornal Brasileiro de Patologia e Medicina Laboratorial 2003;39(4):275-82.

12. Bosso P.A.R., Candeias J.M.G., Paduan K.S., et al. Human Respiratory Syncytial Virus detection in children admitted at a community hospital in Botucatu, SP, Braziç. Brazilian J of Microbiology 2004;35:348-51.

13. Iwane M.K., Edwards K.M., Szilagyi P.G., et al. Population-Based Surveillance for Hospitalization Associated with Respiratory Syncytial Virus, Influenza Virus, and Parainfluenza Viruses among young children. Pediatrics 2004;113(6):1758-64.

14. Spremolla A., Pascale I., Pirez M., et al. Investigacion de virus respiratorios en ninos menores de dos anos hospitalizados por infeccion respiratoria aguda baja. Arch Pediatr Urug 2003;74(3):176-81.
15. Kuypers J., Wright N., Ferrenberg J., et al. Comparison of realtime PCR assays with fluorescent-antibody assays for diagnosis of respiratory virus infections in children. Journal of clinical Microbiology 2006 Jul;44(7):2382-8.

16. Solomon H.E., Grandien M., Avilla M.M., et al. Comparsion of three techiniques for detection of respiratory viruses in nasopharingeal aspirates from children with lower acute respiratory infections. Journal of Medical Virology 1989;28:159-62.

17. Storch G.A. Diagnostic Virology. Philadelphia, New York: Lippincott-Raveen Publishers, 1996.

18. Bonzel L.T.T., Scroten H., Schildgen O., et al. Frequent Detection of Viral Coinfection in Children Hospitalized with Acute Respiratory Tract Infection Using a Real-Time Polymerase Chain Reaction. The Pediatric Infectious Disease Journal 2008 May 29;27(7).

19. Domachowske J.B., Rosenberg H.F. Respiratory syncytial virus infection: immune response, immunopathogenesis, and treatment. Clinical Microbiology Reviews 1999 Apr;12(2):298-309.

20. Thomazelli L.M., Vieira S., Leal A.L., et al. Vigilância de oito vírus respitarórios em amostras clínicas de pacientes pediátricos no sudeste do Brasil. Jornal de Pediatria 2007;83(5):422-8.

21. Durany Y.F.M., Attia M.W. Clinical predictors of respiratory syncytial virus infection in children. Pediatr Int 2008;50(3):352-5.

22. Bricks L.F. Prevention of Respiratory syncytial virus infections. Rev Hosp Clin Fac Med S Paulo 2001;56(3):79-90.

23. Hall C.B. Respiratory syncytial virus and parainfluenzae virus. $\mathrm{N}$ Engl J Med 2001;344(25):1917-28.

24. Vieira S.E., Stewien K.E., Queiroz D.A., et al. Clinical patterns and seasonal trends in respiratory syncytial virus hospitalizations in Sao Paulo, Brazil. Revista do Instituto de Medicina Tropical de Sao Paulo 2001 May-Jun;43(3):125-31.

25. Nascimento J.P., Siqueira M.M., Sutmoller F., et al. Longitudinal study of acute respiratory diseases in Rio de Janeiro: occurrence of respiratory viruses during four consecICUve years. Revista do Instituto de Medicina Tropical de Sao Paulo 1991 Jul-Aug;33(4):287-96.

26. Speranza A.M., Clary A.L., Pereira T., et al. Estudio multicentrico de infecciones respiratorias bajas em ninos hospitalizados menores de dos anos. Arch Argent Pediatr 2003;101(6):365-73.

27. Pediatria S.B. Recomendações para a prevenção de doença grave pelo Respiratory syncytial virus. 2006.

28. The Impact-RVS Group. Palivizumab. A humanized respiratory syncytyial virus monoclona antibody, reduces hospitalization from respiratory synsytial virus infection in high-risck infants. Pediatrics 1998 1998; $102: 531-37$.

29. Rodriguez S.P., Fariña D., Bauer G. Respiratory Syncytial Virus prophylaxis in high-risk population in Argentina: A costeffectivenee analysis. The Pediatric Infectious Disease Journal 2008;27(7).

30. Djelantik I.G., Gessner B.D., Soewignjo S., et al. Incidence and clinical features of hospitalization because of respiratory syncytial virus lower respiratory illness among children less than two years of age in a rural Asian setting. Pediatr Infect Dis J 2003 Feb;22(2):150-7.

31. WHO. Initiative for Vaccine research (IVR) - Acute Respiratory Infections: Respiratory syncytial virus (RSV). 2006 [cited; Available from: http://www.who.int/vaccine_research/diseases/ ari/en/index3.html.

32. Prober C.G., Sullender W.M. Advances in prevention of respiratory syncytial virus infections. The Journal of Pediatrics 1999 Nov;135(5):546-58. 